\title{
Memahami Patofisiologi dan Aspek Klinis Syok Hipovolemik: Update dan Penyegar
}

Hardisman

\begin{abstract}
Abstrak
Secara patofisiologis syok merupakan gangguan hemodinamik yang menyebabkan tidak adekuatnya hantaran oksigen dan perfusi jaringan. Gangguan hemodinamik tersebut dapat berupa penurunan tahanan vaskuler sitemik terutama di arteri, berkurangnya darah balik, penurunan pengisian ventrikel dan sangat kecilnya curah jantung. Gangguan faktor-faktor tersebut disbabkan oleh bermacam-macam proses baik primer pada sistim kardiovaskuler, neurologis ataupun imunologis. Diantara berbagai penyebab syok tersebut, penurunan hebat volume plasma intravaskuler merupakan faktor penyebab utama. Terjadinya penurunan hebat volume intravaskuler dapat terjadi akibat perdarahan atau dehidrasi berat, sehingga menyebabkan yang balik ke jantung berkurang dan curah jantungpun menurun. Penurunan hebat curah jantung menyebabkan hantaran oksigen dan perfusi jaringan tidak optimal dan akhirnya menyebabkan syok. Pada tahap awal dengan perdarahan kurang dari $10 \%$, gejala klinis dapat belum terlihat karena adanya mekanisme kompensasi sisitim kardiovaskuler dan saraf otonom. Baru pada kehilangan darah mulai $15 \%$ gejala dan tanda klinis mulai terlihat berupa peningkatan frekuensi nafas, jantung atau nadi (takikardi), pengisian nadi yang lemah, penurunan tekanan nadi, kulit pucat dan dingin, pengisian kapiler yang lambat dan produksi urin berkurang. Perubahan tekanan darah sistolik lebih lambat terjadi akibat adanya mekanisme kompensasi tadi, sehingga pemeriksaan klinis yang seksama harus dilakukan.
\end{abstract}

Kata kunci: syok, hipovolemik dan patofisiologi

\begin{abstract}
Shock is hemodynamic disorders, which causes inadequate oxygen delivery and perfusion. The hemodynamic disorders can be decreasing of systemic vascular resistant, venous return, ventricular filling and inadequate of cardiac output. The disorders are caused by cardiovascular dysfunction, neurologic or immunologic factors. Intravascular volume loss is one of the main factors, which is caused by severe dehydration or bleeding. These conditions lead to decreasing of venous return and cardiac output that cause inadequate oxygen delivery and perfusion. The homeostatic defence mechanism can compensate the cardiovascular function with the blood loss up to $10 \%$. The clinical symptoms appears when the blood loss 15\%, such as tachypnoea, tachycardia, weak of pulse, decreasing of mean arterial pressure, skin pale and cold, decreasing refilling capillary and urine production. Due to the compensation mechanism, alteration of systolic blood pressure is relatively late; therefore, thorough and complete clinical assessment is necessary.
\end{abstract}

Keywords: shock, hypovolemic and pathophysiology

Affiliasi penulis : Hardisman,

Korespondensi : Bagian Pendidikan Kedokteran, Bagian

Anestesiologi Fakultas Kedokteran Universitas Andalas (Unand),

Padang, email : hardisman@fk.unand.ac.id

\section{Pendahuluan}

Pengertian syok terdapat bermacam-macam sesuai dengan konteks klinis dan tingkat kedalaman analisisnya. Secara patofisiologi syok merupakan gangguan sirkulasi yang diartikan sebagai kondisi tidak adekuatnya transport oksigen ke jaringan atau perfusi yang diakibatkan oleh gangguan hemodinamik. Gangguan hemodinamik tersebut dapat berupa penurunan tahanan vaskuler sitemik terutama di arteri, berkurangnya darah balik, penurunan pengisian ventrikel dan sangat kecilnya curah jantung. Dengan demikian syok dapat terjadi oleh berbagai macam sebab dan dengan melalui berbagai proses. Secara umum dapat dikelompokkan kepada empat komponen yaitu masalah penurunan volume plasma intravaskuler, masalah pompa jantung, masalah pada pembuluh baik arteri, vena, arteriol, venule atupun kapiler, serta sumbatan potensi aliran baik pada jantung, sirkulasi pulmonal dan sitemik. ${ }^{1,2}$

Penurunan hebat volume plasma intravaskuler merupakan faktor utama yang menyebabkan gterjadinya syok. Dengan terjadinya penurunan hebat volume intravaskuler apakah akibat perdarahan atau dehidrasi akibat sebab lain maka darah yang balik ke jantung (venous return) juga berkurang dengan hebat, sehingga curah jantungpun menurun. Pada akhirnya ambilan oksigen di paru juga menurun dan asupan oksigen ke jaringan atau sel (perfusi) juga tidak dapat dipenuhi. Begitu juga halnya bila terjadi gangguan primer di jantung, bila otot-otot jantung melemah yang menyebabkan kontraktilitasnya tidak sempurna, sehingga tidak dapat memompa darah dengan baik dan curah jantungpun menurun. Pada kondisi ini meskipun volume sirkulasi cukup tetapi tidak ada tekanan yang optimal untuk memompakan darah yang dapat memenuhi kebutuhan oksigen jaringan, akibatnya perfusi juga tidak terpenuhi. ${ }^{1-3}$

Gangguan pada pembuluh dapat terjadi pada berbagai tempat, baik arteri (afterload), vena (preload), kapiler dan venula. Penurunan hebat tahanan tahanan vaskuler arteri atau arteriol akan menyebabkan tidak seimbangnya volume cairan intravaskuler dengan pembuluh tersebut sehingga menyebabkan tekanan darah menjadi sangat rendah yang akhirnya juga menyebabkan tidak terpenuhianya perfusi jaringan. Peningkatan tahanan arteri juga dapat mengganggu sistim sirkulasi yang mengakibatkan menurunya ejeksi ventrikel jantung sehingga sirkulasi dan oksigenasi 
jaringan menjadi tidak optimal. Begitu juga bila terjadi peningkatan hebat pada tonus arteriol, yang secara langsung dapat menghambat aliran sirkulasi ke jaringan. Gangguan pada vena dengan terjadinya penurunan tahanan atau dilatasi yang berlebihan menyebabkan sistim darah balik menjadi sehingga pengisian jantung menjadi berkurang pula. Akhirnya menyebabkan volume sekuncup dan curah jantung juga menurun yang tidak mencukupi untuk oksigenasi dan perfusi ke jaringan. Ganguan pada kapiler secara langsung seperti terjadinya sumbatan atau kontriksi sistemik secara langsung menyebabkan terjadinya gangguan perfusi karena area kapiler adalah tempat terjadinya pertukaran gas antara vaskuler dengan jaringan sel-sel tubuh. ${ }^{1-3}$

Berdasarkan bermacam-macam sebab dan kesamaan mekanisme terjadinya itu syok dapat dikelompokkan menjadi beberapa empat macam yaitu syok hipovolemik, syok distributif, syok obstrukttif, dan syok kardiogenik. ${ }^{1,2}$

\section{Syok Hipovolemik}

Syok hipovolemik merupakan syok yang terjadi akaibat berkurangnya volume plasma di intravaskuler. Syok ini dapat terjadi akibat perdarahan hebat (hemoragik), trauma yang menyebabkan perpindahan cairan (ekstravasasi) ke ruang tubuh non fungsional, dan dehidrasi berat oleh berbagai sebab seperti luka bakar dan diare berat. Kasus-kasus syok hipovolemik yang paing sering ditemukan disebabkan oleh perdarahan sehingga syok hipovolemik dikenal juga dengan syok hemoragik. Perdarahan hebat dapat disebabkan oleh berbagai trauma hebat pada organorgan tubuh atau fraktur yang yang disertai dengan luka ataupun luka langsung pada pembuluh arteri utama. ${ }^{2,4,5}$

\section{Peranan Fisiologis Sisitim Kardiovaskuler dan Saraf pada Syok}

Untuk memahami patofisiologi atau memahami proses terjadinya berbagai jenis syok terutama syok hipovolemik, maka pemahaman fisiologi jantung, sirkulasi dan sisitim saraf sangat diperlukan.

\section{Peranan Fungsi Kardiovaskuler}

Jantung merupakan organ yang berfungsi untuk memompakan darah keseluruh tubuh. Jantung bergerak secara otonom yang diatur melalui mekanisme sistim saraf otonom dan hormonal dengan autoregulasi terhadap kebutuhan metabolime tubuh. Mekanisme otonom aktifitas otot jantung ini berasal dari cetusan listrik (depolarisasi) pada otot jantung itu sendiri. Depolarisai otonom otot jantung berasal dari sekelompok sel-sel yang menghasilkan potensial listrik yang disebut dengan nodus sinoatrial [sinoatratrial (SA) node]. SA node terletak di atrium kanan berdekatan dengan muara vena cava superior. ${ }^{6,7}$

Impuls listrik yang dihasilkan oleh $S A$ node akan dialirkan keseluruh otot-otot jantung (miokardium) sehingga menyebabkan kontraksi. Mekanisme penyebaran impuls ini teratur sedemikian rupa sesuai dengan siklur kerja jantung. Pertama impuls dialirkan secara langsung ke otot-otot atrium kiri dan kanan sehingga menyebabkan kontraksi atrium. Atrium kanan yang berisi darah yang berasal dari sistim vena sitemik akan dipompakan ke ventrikel kana, dan darah pada atrium kiri yang berasl dari paru (vena pulmonalis) akan dialirkan ke ventrikel kiri. Selanjutnya impuls diteruskan ke ventrikel melalui sistim konduksi nodus atrioventrikuler [atrioventricular (AV) node], terus ke atrioventricular (AV) bundle dan oleh serabut purkinje ke seluruh sel-sel otot ventrikel jantung. Impils listrik yang ada di ventrikel terjadinya depolarisasi dan selanjutnya menyebabkan otot-otot ventrikel berkontraksi. Kontraksi ventrikel inilah yang dikenal sebagai denyut jantung. Denyut ventrikel kanan akan mengalirkan darah ke paru untuk pengambilan oksigen dan pelepasan karbondioksida, dan denyut ventrikel kiri akan mengalirkan darah ke seleuruh tubuh melalui aorta. Denyut jantung yang berasal dari depolarisai $S A$ node berjumlah 60-100 kali permenit, dengan rata-rat 72 kali permenit. ${ }^{6,7}$

Kontraksi ventrikel saat mengeluarkan darah dari jantung disebut sebagai fase sitolik atau ejeksi ventrukuler. Jumlah darah yang dikeluarkan dalam satu kali pompan pada fase ejeksi ventrikuler disebut sebagai 'volume sekuncup' atau stroke volume, dan pada dewasa rata-rata berjumlah $70 \mathrm{ml}$. Dengan jumlah kontraksi rata-rata 72 kali permenit, maka dalam satu menit jumlah darah yang sudah melewati dan diponpakan oleh jantung sekitar 5 liter, yang dsiebut sebagai curah jantung (cardiac output). Secara matematis fisiologis dapat dirumuskan sesuai gambar 1.

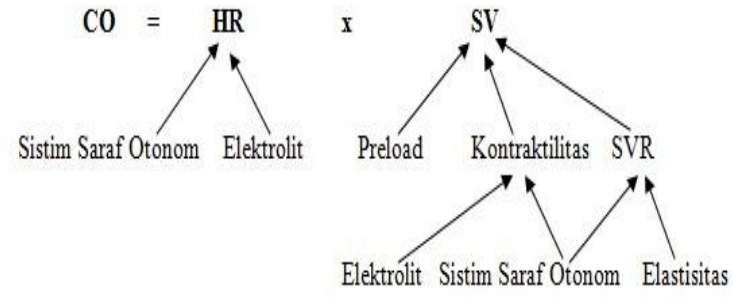

Keterangan:

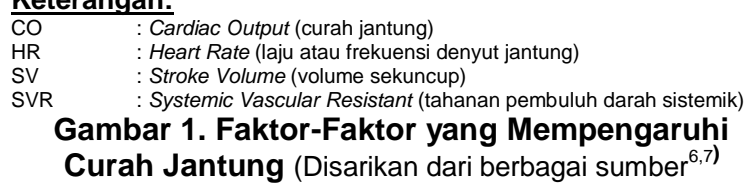

Aktifitas listrik pada $S A$ node yang menyebabkan kontraksi otot jantung terjadi secara otonom tanpa kontrol pusat kesadaran yang dipengaruhi oleh sistim saraf otonom simpatis dan parasimpatis. Dengan demikian seperti yang terlihat pada gambar-1, sistim saraf otonom sangat berperan dalam pengaturan kardiovaskuler dengan mempengaruhi frekuensi denyut dan kontraktilitas otot jantung. Disamping itu sisitim saraf otonom juga mempengaruhi pembuluh darah terhadap perubahan resistensi pembuluh darah.

Curah jantung mempunyai peranan penting sebagai salah satu faktor untuk memenuhi kebutuhan oksigenasi atau perfusi kejaringan sebagai tujuan dari fungsi kardiovaskuler. Kecukupan perfusi jaringan ditentukan oleh kemampuan fungsi sirkulasi menghantarkan oksigen ke jaringan yang disebut sebagai oxygen delivery $\left(\mathrm{DO}_{2}\right)$, dan curah jantung adalah faktor utama yang menentukan $\mathrm{DO}_{2}$ ini, sebagaimana yang dapat dilihat pada gambar-2. 


$$
\begin{aligned}
\mathrm{DO}_{2} & =\mathrm{CO} \times \mathrm{CaO}_{2} \\
\rightarrow & \mathrm{CaO}_{2}=\left(1,34 \times \mathrm{Hb} \times \mathrm{SaO}_{2}\right)+\left(0,00031 \times \mathrm{PaO}_{2}\right) \\
\mathrm{DO}_{2} & \left.=\mathrm{CO} \times\left(1,34 \times \mathrm{Hb}_{\mathrm{SaO}}\right)+\left(0,00031 \times \mathrm{PaO}_{2}\right)\right]
\end{aligned}
$$

$\rightarrow \mathrm{CaO}_{2}=20 \mathrm{ml} \mathrm{O} / \mathrm{dL}$ darah (rata-rata pada dewasa)

$\rightarrow \mathrm{CO}=5 \mathrm{Liter} / \mathrm{menit}=50 \mathrm{dL} /$ menit (rata-rata pada dewasa)

$\mathrm{DO}_{2}=50 \mathrm{dL} \times 20 \mathrm{ml} \mathrm{O} / \mathrm{dL}=1000 \mathrm{mlO} /$ menit

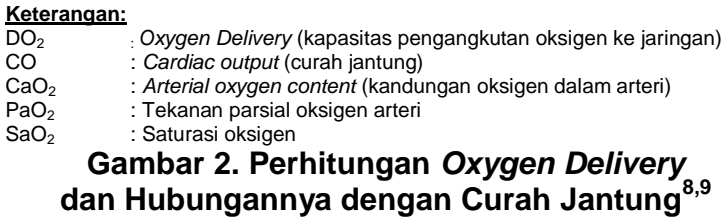

Gangguan pada faktor-faktor yang mepengaruhi curah jantung dapat mengakibatkan terjadinya gangguan perfusi dan berujung kepada syok. Misalnya kehilangan volume plasma hebat akan mengurangi preload dan dapat mengakibatkan terjadinya syok hipovolemik, gangguan kontraktilitas dapat mengakibatkan terjadinya syok kardiogenik, dan gangguan resistensi vaskuler sitemik dapat berujung ada syok distributif.

\section{Peranan Fungsi Sistim Saraf Otonom}

Sistim saraf otonom dibedakan menjadi dua macam, yaitu sistim saraf simpatis dan para simpatis. Sistim saraf simpatis merupakan sistim saraf yang bekerja secara otonom terhadap respon stress psikis dan aktifitas fisik. Respon simpatis terhadap stress disebut juga sebagai 'faight of flight response' memberikan umpan balik yang spesisfik pada organ dan sistim organ, termasuk yang paling utama adalah respon kardiovaskuler, pernafasan dan sistim imun. Sedangkan sistim para simpatis mengatur fungsi tubuh secara otonom terutama pada organ-organ visceral, produksi kelenjar, fungsi kardiovaskuler dan berbagai sistim organ lainnya dan bukan respon terhadap suatu stressor ataupun aktifitas fisik. ${ }^{10,11}$

Sistim saraf simpatis berasal dari medulla spinalis pada segmen torakolumbal, tepatnya segmen torakal-1 sampai lumbal-2, dengan pusat ganglion sarafnya berada di daerah paravertebre. Sistim saraf simpatis menimbulkan efek pada organ dan sistim organ melalui perantra neurotrasmiter adrenalin (epinefrin) atau noradrenalin (norepinefrin) endogen yang dhasilkan oleh tubuh. Adrenalin di sekresikan oleh kelenjar adrenal bagian medula, sedangkan noradrenalin selain dihasilkan oleh medulla adrenal juga disekresikan juga oleh sel-sel saraf (neutron) simpatis pascaganglion. ${ }^{10,11}$

Respon yang muncul pada organ-organ target tergantung reseptor yang menerima neurotrasmiter tersebut yang dikenal dengan reseptor alfa dan beta adrenergik. Pada jantung terdapat resesptor beta, rangsangan simpatis pada otot jantung atau reaksi adrenalin dengan reseptor beta- 1 menyebabkan peningkatan frekuensi (kronotropik) dan kontraktilitas otot jantung (inotropik). Efek adrenergik pada pembuluh terjadi melalui reaksi neurotrasmiternya dengan reseptor alfa-1, yang menyebabkan terjadinya vasokontriksi arteri dan vena. Sedangkan efek pada saluran pernafasan terutama bronkhus adalah dilatasi (melalui reseptor beta-2). ${ }^{10,11}$
Sistim parasismpatis dari segmen kraniosakral, yaitu dari saraf kranial dan medulla spinalis sekmen sakralis. Saraf kranial merupakan saraf tepi yang langsung keluar dari batang otak dan terdapat 12 pasang, namun yang memberikan efek parasimpatis yaitu nervus-III (okulomotorius), nervusVII (fasialis), nervus-IX (glosofaringeus) dan nervus-X (vagus). Rangsangan parasimpatis pada masingmasing saraf tersebut memberikan efek spesifik pada masing-masing organ target, namun yang memberikan efek terhadap fungsi kardiovaskuler adalah nervus vagus. Sedangkan yang berasal dari medulla spinalis yang menimbulkan efek parasimpatis adalah berasal dari daerah sakral-2 hingga 4.

Efek parasimpatis muncul melalui perantara neurotrasnmiter asetilkolin, yang disekresikan oleh semua neuron pascaganglion sisitim saraf otonom parasimpatis. Efek parasimpatis ini disebut juga dengan efek kolinergik atau muskarinik. Sebagaimana halnya sistim saraf simpatis, sistim saraf parsimpatis juga menimbulkan efek bermacam-macam sesuai dengan reaksi neurotransmitter asetilkolin dengan reseptornya pada organ target. Efek yang paling dominan pada fungsi kardiovaskuler adalah penurunan frekuensi jantung dan kontraktilitasnya (negatif kronotropik dan inotropik) serta dilatasi pembuluh darah.

Dalam kedaan fisiologis, kedua sistim saraf ini mengatur funsgi tubuh termasuk kardiovaskuler secara homeostatik melalui mekanisme autoregulasi. Misalnya pada saat aktifitas fisik meningkat, tubuh membutuhkan energi dan metabolisme lebih banyak dan konsumsi oksigen meningkat, maka sistim simpatis sebagai respon homestatik akan meningkatkan frekuensi denyut dan kontraktilitas otot jantung, sehingga curah jantung dapat ditingkatkan untuk untuk mensuplai oksigen lebih banyak. Begitu juga bila terjadi kehilangan darah, maka respon simpatis adalah dengan terjadinya peningkatan laju dan kontraktilitas jantung serta vasokontriksi pembuluh darah, sehingga kesimbangan volume dalam sirkulasi dapat terjaga dan curah jantung dapat dipertahankan. Namun bila gangguan yang terjadi sangat berlebihan, maka kompensasi autoregulasi tidak dapat lagi dilakukan sehingga menimbulkan gejala-gejala klinis. 7,12

\section{Patofisiologi dan Gambaran Klinis}

Gejala-gejala klinis pada suatu perdarahan bisa belum terlihat jika kekurangan darah kurang dari 10\% dari total volume darah karena pada saat ini masih dapat dikompensasi oleh tubuh dengan meningkatkan tahanan pembuluh dan frekuensi dan kontraktilitas otot jantung. Bila perdarahan terus berlangsung maka tubuh tidak mampu lagi mengkompensasinya dan menimbulkan gejala-gejala klinis. Secara umum syok hipovolemik menimbulkan gejala peningkatan frekuensi jantung dan nadi (takikardi), pengisian nadi yang lemah, kulit dingin dengan turgor yang jelek, ujung-ujung ektremitas yang dingin dan pengisian kapiler yang lambat. $^{1-3}$

Pemeriksaan yang dilakukan untuk menegakkan diagnosis adanya syok hipovolemik tersebut pemeriksaan pengisian dan frekuesnsi nadi, tekanan darah, pengisian kapiler yang dilakukan pada ujung-uung jari (refiling kapiler), suhu dan turgor kulit. Berdasarkan persentase volume kehilangan darah, syok hipovolemik dapat dibedakan menjadi empat tingkatan atau stadium. Stadium syok dibagi 
berdasarkan persentase kehilangan darah sama halnya dengan perhitungan skor tenis lapangan, yaitu $15,15-30,30-40$, dan $>40 \%$. Setiap stadium syok hipovolemik ini dapat dibedakan dengan pemeriksaan klinis tersebut. ${ }^{1-3,13}$

1. Stadium-I adalah syok hipovolemik yang terjadi pada kehilangan darah hingga maksimal 15\% dari total volume darah. Pada stadium ini tubuh mengkompensai dengan dengan vasokontriksi perifer sehingga terjadi penurunan refiling kapiler. Pada saat ini pasien juga menjadi sedkit cemas atau gelisah, namun tekanan darah dan tekanan nadi rata-rata, frekuensi nadi dan nafas masih dalam kedaan normal.

2. Syok hipovolemik stadium-II afalah jika terjadi perdarahan sekitar $15-30 \%$. Pada stadium ini vasokontriksi arteri tidak lagi mampu menkompensasi fungsi kardiosirkulasi, sehingga terjadi takikardi, penurunan tekanan darah terutama sistolik dan tekanan nadi, refiling kapiler yang melambat, peningkatan frekuensi nafas dan pasien menjadi lebih cemas.

3. Syok hipovolemik stadium-III bila terjadi perdarahan sebanyak 30-40\%. Gejala-gejala yang muncul pada stadium-II menjadi semakin berat. Frekuensi nadi terus meningkat hingga diatas 120 kali permenit, peningkatan frekuensi nafas hingga diatas 30 kali permenit, tekanan nadi dan tekanan darah sistolik sangat menurun, refiling kapiler yang sangat lambat.

4. Stadium-IV adalah syok hipovolemik pada kehilangan darah lebih dari $40 \%$. Pada saat ini takikardi lebih dari 140 kali permenit dengan pengisian lemah sampai tidak teraba, dengan gejala-gejala klinis pada stadium-III terus memburuk. Kehilangan volume sirkulasi lebih dari $40 \%$ menyebabkan terjadinya hipotensi berat, tekanan nadi semakin kecil dan disertai dengan penurunan kesadaran atau letargik.

Selengkapnya stadium dan tanda-tanda klinis pada syok hemoragik dapat dilihat oada tabel-1.

Tabel 1. Stadium Syok Hipovolemik dan Gambaran Klinisnya

\begin{tabular}{|c|c|c|c|c|}
\hline $\begin{array}{c}\text { Tanda dan } \\
\text { Pemeriksaan } \\
\text { Klinis }\end{array}$ & $\underset{\text { I }}{\text { Stadium- }}$ & $\begin{array}{l}\text { Stadium- } \\
\text { II }\end{array}$ & $\begin{array}{l}\text { Stadium- } \\
\text { III }\end{array}$ & $\begin{array}{l}\text { Stadium- } \\
\text { IV }\end{array}$ \\
\hline $\begin{array}{l}\text { Kehilangan } \\
\text { Darah (\%) }\end{array}$ & $15 \%$ & $15-30 \%$ & $30-40 \%$ & $>40 \%$ \\
\hline Kesadaran & $\begin{array}{l}\text { Sedikit } \\
\text { cemas }\end{array}$ & Cemas & $\begin{array}{l}\text { Sangat } \\
\text { Cemas/ } \\
\text { Bingung }\end{array}$ & Letargi \\
\hline $\begin{array}{l}\text { Frekuensi } \\
\text { Jantung atau } \\
\text { Nadi }\end{array}$ & $\begin{array}{c}<100 x / m e \\
\text { nit }\end{array}$ & $\begin{array}{c}>100- \\
120 x / m e n \\
\text { it }\end{array}$ & $\begin{array}{c}>120- \\
140 x / \text { men } \\
\text { it }\end{array}$ & $\begin{array}{c}>140 x / m e n \\
\text { it }\end{array}$ \\
\hline $\begin{array}{l}\text { Frekuensi } \\
\text { Nafas }\end{array}$ & $\begin{array}{c}14- \\
20 x / \text { menit }\end{array}$ & $\begin{array}{c}20- \\
30 \times / \text { menit }\end{array}$ & $\begin{array}{c}30- \\
40 x / \text { menit } \\
\end{array}$ & $>35 x /$ menit \\
\hline $\begin{array}{l}\text { Refiling } \\
\text { Kapiler }\end{array}$ & Lambat & Lambat & Lambat & Lambat \\
\hline $\begin{array}{l}\text { Tekanan } \\
\text { Darah Sistolik }\end{array}$ & Normal & Normal & Turun & Turun \\
\hline Tekanan Nadi & Normal & Turun & Turun & Turun \\
\hline Produksi Urin & $\begin{array}{c}>30 \mathrm{ml} / \mathrm{Ja} \\
\mathrm{m}\end{array}$ & $\begin{array}{c}20- \\
30 \mathrm{ml} / \mathrm{Jam}\end{array}$ & $\begin{array}{c}5- \\
15 \mathrm{ml} / \mathrm{Jam}\end{array}$ & $\begin{array}{l}\text { Sangat } \\
\text { sedikit }\end{array}$ \\
\hline
\end{tabular}

Berdasarkan perjalanan klinis syok seiring dengan jumlah kehilangan darah terlihat bahwa penurunan refiling kapiler, tekanan nadi dan produksi urin lebih dulu terjadi dari pada penurunan tekanan darah sistolik. Oleh karena itu, pemeriksaan klinis yang seksama sangat penting dilakukan. Pemeriksaan yang hanya berdasarkan perubahan tekanan darah sitolik dan frekuensi nadi dapat meyebabkan kesalahan atau keterlambatan diagnosoa dan penatalaksanaan (neglected cases).

Tekanan nadi (mean arterial pressure: MAP) merupakan merupakan tekanan efektif rata-rata pada aliran darah dalam arteri. Secara matematis tekanan ini dipadapatkan dari penjumlahan tekanan sistolik dengan dua kali tekanan diastolik kemudian dibagi tiga (seperti yang terlihat pada gambar-3).

$$
\begin{aligned}
& \text { TN }=\text { TD }+[1 / 3(T S-T D)] \\
& \text { atau } \\
& \text { TN }=\underline{T S+2 T D}
\end{aligned}
$$

$$
\begin{array}{ll}
\text { Keterangan: } & \\
\text { TN } & \text { : Tekanan Nadi Rata-Rata } \\
\text { TS } & \text { : Tekanan Darah Sistolik } \\
\text { TD } & \text { : Tekanan Darah Diastolik }
\end{array}
$$

Gambar 3. Perhitungan Tekanan Nadi Rata-Rata ${ }^{2,14}$

Penurunan tekanan darah sistolik lebih lambat terjadi karena adanya mekanisme kompensasi tubuh terhadap terjadinya hipovolemia. Pada awalawal terjadinya kehilangan darah, terjadi respon sistim saraf simpatis yang mengakibatkan peningkatan kontraktilitas dan frekuensi jantung. Dengan demikian pada tahap awal tekanan darah sistolik dapat dipertahankan. Namun kompensasi yang terjadi tidak banyak pada pembuuh perifer sehingga telah terjadi penurunan diastolik sehingga secara bermakna akan terjadi penurunan tekanan nadi rata-rata. ${ }^{13}$

Berdasarkan kemampuan respon tubuh terhadap kehilangan volume sirkulasi tersebut maka secara klinis tahap syok hipovolemik dapat dibedakan menjadi tiga tahapan yaitu tahapan kompensasi, tahapan dekompensasi dan tahapan irevesrsibel. Pada tahapan kompensasi, mekanisme autoregulasi tubuh masih dapat mempertahankan fungsi srikulasi dengan meningkatkan respon simpatis. Pada tahapan dekompensasi, tubuh tidak mampu lagi mempertahankan fungsinya dengan baik untuk seluruh organ dan sistim organ. Pada tahapan ini melalui mekanisme autoregulasi tubuh berupaya memberikan perfusi ke jaringan organ-organ vital terutama otak dan terjadi penurunan aliran darah ke ekstremitas. Akibatnya ujung-ujung jari lengan dan tungkai mulai pucat dan terasa dingin. Selanjutnya pada tahapan ireversibel terjadi bila kehilangan darah terus berlanjut sehingga menyebabkan kerusakan organ yang menetap dan tidak dapat diperbaiki. Kedaan klinis yang paling nyata adalah terjadinya kerusakan sistim filtrasi ginjal yang disebut sebagai gagal ginjal akut. ${ }^{3,5}$

\section{Prinsip Penatalaksanaan}

Penatalaksanaan syok hipovolemik meliputi mengembalikan tanda-tanda vital dan hemodinamik kepada kondisi dalam batas normal. Selanjutnya kondisi tersebut dipertahankan dan dijaga agar tetap pada kondisi satabil. Penatalaksanaan syok hipovolemik tersebut yang utama terapi cairan sebagai pengganti cairan tubuh atau darah yang hilang. Jika ditemukan oleh petugas dokter atau petugas medis, maka penatalaksanaan syok harus dilakukan secara komprehensif yang meliputi penatalaksanaan sebelum 
dan di tempat pelayanan kesehatan atau rumah sakit. $^{3-5,15}$

Penatalaksanaan sebelum di tempat pelayanan kesehatan harus memperhatikan prinsipprinsip tahapan resusitasi. Selanjutnya bila kondisi jantung, jalan nafas dan respirasi dapat dipertahankan, tindakan selanjutnya adalah adalah menghentikan trauma penyebab perdarahan yang terjadi dan mencegah perdarahan berlanjut. Menghentikan perdarahan sumber perdarahan dan jika memungkinkan melakukan resusitasi cairan secepat mungkin. Selanjutnya dibawa ke tempat pelayaan kesehatan, dan yang perlu diperhatikan juga adalah teknik mobilisai dan pemantauan selama perjalanan. Perlu juga diperhatikan posisi pasien yang dapat membantu mencegah kondisi syok menjadi lebih buruk, misalnya posisi pasien trauma agar tidak memperberat trauma dan perdarahan yang terjadi, pada wanita hamil dimiringkan kea rah kiri agar kehamilannya tidak menekan vena cava inferior yang dapat memperburuh fungsi sirkulasi. Sedangkan saat ini posisi tredelenberg tidak dianjurkan lagi karena justru dapat memperburuk fungsi ventilasi paru. ${ }^{4,15}$

Pada pusat layanan kesehatan atau dapat dimulai sebelumnya harus dilakukan pemasangan infus intravena. Cairan resusitasi yang digunakan adalah cairan isotonik $\mathrm{NaCl} 0,9 \%$ atau ringer laktat. Pemberian awal adalah dengan tetesan cepat sekitar $20 \mathrm{ml} / \mathrm{KgBB}$ pada anak atau sekitar 1-2 liter pada orang dewasa. Pemberian cairan terus dilanjutkan bersamaan dengan pemantauan tanda vital dan hemodinamiknya. Jika terdapat perbaikan hemodinamik, maka pemberian kristaloid terus dilanjutnya. Pemberian cairan kristaloid sekitar 5 kali lipat perkiraan volume darah yang hilang dalam waktu satu jam, karena istribusi cairan koloid lebih cepat berpindah dari intravaskuler ke ruang intersisial. Jika tidak terjadi perbaikan hemodinamik maka pilihannya adalah dengan pemberian koloid, dan dipersiapkan pemberian darah segera. ${ }^{4,15}$

\section{Kesimpulan}

Syok hipovolemik merupakan kegagalan perfusi jaringan yang disebabkan oleh kehilangan cairan intravaskuler. Proses kegagalan perfusi akibat kehilangan volume intravaskuler terjadi melalui penurunan aliran darah balik ke jantung (venous return) yang menyebabkan volume sekuncup dan curah jantung berkurang. Penurunan hebat curah jantung menyebabkan hantaran oksigen dan perfusi jaringan tidak optimal yang dalam kedaan berat menyebabkan syok. Gejala klinis syok hipovolemik baru jelas terlihat bila kekurangan volume sirkulasi lebih dari $15 \%$ karena pada tahap awal perdarahan kurang mekanisme kompensasi sisitim kardiovaskuler dan saraf otonom masih dapat menjaga fungsi sirkulasi dalam kedaan normal. Gejala dan tanda klinis juga tidak muncul pada waktu bersamaan, seperti perubahan tekanan darah sitolik terjadi lebih lambat dari adanya perubahan tekanan nadi, frekuensi jantung dan penurunan produksi urin. Oleh karena itu pemeriksaan dan penatalaksanaan yang cermat harus dilakukan untuk penatalaksanaan yang tepat, serta penanggulangan segera kasus-kasus yang beresiko agar tidak jatuh kedalam kondisi syok.

\section{Ucapan Terimakasih}

Terimakasih penulis ucapkan kepada dr.Nasman Puar, SpAn Ketua Bagian Anestesiologi dan Terapi
Intensif FK-Unand/ SMF RS M Djamil Padang dan dr. Rinal Efendi yang telah memberikan masukan dan diskusi yang sangat berharga untuk draf awal tulisan ini. Tidak ada konflik kepentingan dan sponsorsip pada tulisan ini.

\section{Kepustakaan}

1. George $Y$, Harijanto E, Wahyuprajitno B. Syok: Definisi, Klasifikasi dan Patofisiologi. In: Harijanto E, editor. Panduan Tatalaksana Terapi Cairan Perioperatif. Jakarta: Perhimpunan Dokter Spesialis Anestesiologi dan Reanimasi Indonesia; 2009. p. 16-36.

2. Guyton A, Hall J. Circulatory Shock and Physiology of Its Treatment (Chapter 24). Textbook of Medical Physiology. 12th ed. Philadelphia, Pensylvania: Saunders; 2010. p. 273-84.

3. Armstrong DJ. Shock. In: Alexander MF, Fawcett JN, Runciman PJ, editors. Nursing Practice Hospital and Home. 2nd ed. Edinburg: Churchill Livingstone; 2004.

4. Kolecki P, Menckhoff CR, Dire DJ, Talavera F, Kazzi AA, Halamka JD, et al. Hypovolemic Shock Treatment \& Management 2013: Available from: http://emedicine.medscape.com/article/760145treatment.

5. Pascoe S, Lynch J. Management of Hypovolaemic Shock in Trauma Patient. Committee NICPG, Sisson G, Parr M, Sugrue M, editors. Sydney: ITIM (Institute of Trauma and Injury Management) NSW Health; 2007.

6. Guyton A, Hall J. The Heart (Unit III, Chapter 9-13). Textbook of Medical Physiology. 12th ed. Philadelphia, Pensylvania: Saunders; 2010. p. 45300.

7. Preston RR, Wilson T. Physiology: Lippincott's Illustrated Reviews Series. Philadelphia: Lippincott Williams \& Wilkins; 2012.

8. Soenarto RF. Fisiologi Kardiovaskuler. In: Soenarto RF, Chandra S, editors. Buku Ajar Anestesiologi. Jakarta: FKUI; 2012. p. 75-89.

9. Guyton A, Hall J. Circulation (Unit IV, Chapter 1424). Textbook of Medical Physiology. 12th ed. Philadelphia, Pensylvania: Saunders; 2010. p. 45300.

10. Silverthorn DU. Human Physiology: An Integrated Approach. 5th ed: Benjamin-Cummings Publishing Company; 2011.

11. Hidayat JK. Fisiologi Susunan Saraf Otonom. In: Soenarto RF, Chandra S, editors. Buku Ajar Anestesiologi. Jakarta: FKUI; 2012. p. 91-9.

12. Costanzo L. Physiology Cases and Problems. 4th ed. Philadelphia: Lippincott Williams \& Wilkins; 2012.

13. Worthley LIG. Shock: a review of pathophysiology and management: Part I Critical Care and Resuscitation. 2000;2:55-65.

14. Morgan G, Mikhail M, Murray M. Fluid Management and Transfusion Clinical Anesthesiology. 4th ed. New York: Lange Medical Books/ McGraw-Hil; 2006. p. 690-707.

15. Udeani J, Kaplan LJ, Talavera F, Sheridan RL, Rice TD, Geibel J. Hemorrhagic Shock 2013: Available from: http://emedicine.medscape.com/article/432650overview\#showall. 